next with 2,400 (23 per cent), and mathematicians with 1,500 (13 per cent). For biologists the figures are $600(12.5$ per cent) ; for geologists, $200(22.0$ per cent); and for other scientists, 300 (11.0 per cent). Among engineers the greatest demand in numbers is expected for mining and other engineers $(8,800$ or $33 \cdot 0$ per cent), for electrical engineers $(5,100$ or $23 \cdot 0$ per cent) and for civil engineers $(3,400$ or $27 \cdot 0$ per cent). For metallurgists the figures are 1,200 (38.0 per cent); mechanical engineers, 1,000 (26.0 per cent); chemical engineers, $700 \quad(47 \cdot 0$ per cent); and for engineers in teaching, $600(25 \cdot 0$ per cent).

The Committee on Scientific Man-power bases its assessment of the long-term demand for scientists and engineers on the assumption of an overall expansion of industrial output of 4 per cent a year, and that this is only possible if there is an adequate supply of scientists and technologists. This involves assumptions of increases of 7 per cent and $5 \cdot 25$ per cent for the chemical and engineering industries, whereas only 2.5 per cent is assumed for the textile industry. Replies received to the Ministry of Labour questionnaire indicate that, without qualification, manufacturing industry expects to employ 37 per cent more scientists and engineers in 1959 than in 1956 ; but this figure reflects a considerable margin for current shortages of qualified men. The Committee attempted to isolate this element by assuming that the demand for trained man-power in each industry would, at the least, rise in relation to the number now employed by the same proportion as output is expected to do over the next three years. The difference between this estimate and the figure supplied by industry is taken to represent the presumed current shortage; and an allowance for this factor has been added to the number currently employed, before making the extrapolations based on changes in output over the next ten years. The result is an estimate of the demand for scientific man-power in terms of the number of scientists and engineers necessary to permit an increase in industrial output of 4 per cent per annum.
The estimates for government departments are based on existing policies and allow only for a very modest increase over the next ten years. Sufficient teachers are postulated to deal with the increased number in secondary schools, but not for any further concentration on scientific subjects or for any improvement in existing staffing ratios, for which about four thousand additional science graduates would be a reasonable assumption. Requirements of the universities are assumed to increase by about 100 per cent over the period.

The broad conclusion is reached that an increase of rather more than 60 per cent is required--from about 135,000 to about 220,000 in 1966 -the increase for engineers being about 70 per cent and for scientists about 50 per cent. The annual gross flow of those qualified in pure and applied science from the universities and technical colleges is to-day a little more than 10,000 -roughly about half scientists and half engineers-and this could well rise to 12,000 by $1958-59$. During the next five years, some 60,000 people qualified in science and engineering might come from the universities and technical colleges of Great Britain; but this would have to rise to 16,000 a year if the figure of $22,0,000$ is to be reached by 1966. Allowing 25 per cent for overseas students, emigration, etc., and some continued measure of shortage, the Committee estimates that an annual output of 16,900 in 1966 and 19,900 in 1970 is required.

The Committee recognizes that its estimates involve some margin of error, but it points out that it may well have taken too conservative a view of the demand that is likely to develop in some sectors of the economy. It suggests, however, that the estimates point to a reasonable objective for the universities and technical colleges. In conclusion, the Committee emphasizes that, at the national level, an annual figure of 'graduations' in pure and applied science of about 20,000, as compared with the present 10,000 , is the minimum at which we should aim over the next ten to fifteen years, if the economy of Britain is to grow at an acceptable rate.

\title{
METALS IN LIVING SYSTEMS
}

A SYMPOSIUM on "Metals in Living Systems" occupied the morning session on September 3 of Section B (Chemistry) during the recent Sheffield meeting of the British Association. It was opened by Sir Rudolph Peters with a few remarks about the role of metals in a variety of enzyme reactions and the importance of metals for the metabolism of all forms of life. He gave some examples of how the biochemist could elucidate the actual function of a metal in an enzymic reaction. In particular, he mentioned the importance of the complex formation between metals and sulphydryl groups as shown, for example, in the interaction of ferrous iron, cysteine and aconitase, studied in his laboratory by Morrison. Sir Rudolph emphasized the complexity of some of the problems by referring to the recent work on the composition of xanthine oxidase.

Prof. A. Neuberger (London) discussed the structure and biogenesis of porphyrins and related compounds. Simple pyrroles have so far not been found in Nature, with the notable exception of the aminomethyl pyrrole, porphobilinogen, which is an intermediate in the biosynthesis of porphyrins and is excreted in the urine of patients suffering from acute porphyria. Much more widespread - and of the greatest im. portance in connexion with the present discussionare the macrocyclic tetrapyrrolic structures found in hæmoglobin, chlorophyll and vitamin $\mathrm{B}_{12}$. Prof. Neuberger first discussed the porphyrins forming part of the hæmoglobin, catalase and peroxidase molecules and the type of resonance found in the porphyrin structure. He then briefly considered the types of bond formed between the central iron atom in hæm and the heterocyclic pyrrolic systems. The interaction between the hæm and protein moiety of the hæm proteins was considered and the various types of isomers arising from changes in the order of the 'outer' substituents of the porphyrin ring were mentioned. Turning to the chlorophylls, Prof. Neu. berger pointed out that these contain as the central atom not iron, but magnesium, and also differ from the hæm compounds in the degree of saturation of the heterocyclic system. The work of linstead and his co-workers on the location of the 'extra' hydrogen 
atom in the chlorophyll molecule was also mentioned. The third type of macrocyclic pyrrolic structure considered was that present in vitamin $B_{12}$. In this molecule, as shown by Dr. D. C. Hodgkin and Sir Alexander Todd, the macrocyclic system is reduced to a much greater extent than in porphyrins or chlorophyll, and not all the pyrrolic rings are linked, as in the porphyrins or chlorophyll, by methene bridges. Two of the rings are joined by a direct linkage, giving a dipyrryl structure. In addition, the central atom is cobalt.

Prof. Neuberger then traced the development of recent work on the biosynthesis of porphyrins, starting from the discovery in 1946 by Shemin and Rittenberg that the nitrogen atom of glycine is specifically used in the biosynthesis of porphyrin. He described work done in the department of Shemin and in his own laboratory, work which was muinly based on isotope techniques. 'The isolation of porphobilinogen by Westall and the elucidation of its structure by Cookson and Rimington in 1953 completed the overall picture. Glycine is condensed with an asymmetrically substituted derivative of succinic acid to give $\alpha$-amino $\beta$-oxoadipate, which loses carbon dioxide to yield $\delta$-aminolævulic acid. Condensations of two molecules of the latter then give porphobilinogen. While the last reaction has been shown to be catalysed by a specific enzyme which has been obtained in a purified form, the initial condensation reaction has not yet been clarified at the enzymic level. Prof. Neuberger mentioned experiments done in his own laboratory which indicated that $\alpha$-amino $\beta$-oxoadipic acid is extremely unstable, and it seems uncertain whether it will ever be made by chemical methods. The possibility exists that this $x$-amino B-keto acid never occurs as such in the biogenesis of the porphyrin ring. The further changes involved in the conversion of porphobilinogen to the naturally occurring porphyrins were then considered. Fxperiments of Granick and others indicating that porphyrins are precursors of chlorophyll were then described. Prof. Neuberger concluded by saying that the initial steps in the biosynthesis of the macrocyclic system of vitamin $B_{12}$ are probably identical with those established for porphyrins.

Dr. C. P. Whittingham (Cambridge) spoke on "The Role of Metals in the Green Plant" and started his talk by briefly referring to some nutritional problems met with in ordinary farming and horticulture. For example, potassium is required in more than trace amounts; but other metals which have recently been shown to be important and which are needed in relatively small amounts are manganese, zinc, copper and molybdenum. The plant physiologist who wishes to find out what part a particular metal plays in the metabolism of a plant may observe the physiological effects which result from either using a deficient medium or the addition of a metal poison, that is, a substance combining with a particular metal or a group of metals. This approach was illustrated by some experiments showing the effects of the addition of such poisons to processes such as photosynthesis, nitrate reduction and respiration in Chlorella. Another example was the well-known experiment by Warburg in which the inhibitory effect of carbon monoxide on the respiration of yeast is partially removed by illumination. Since it is known that light of the particular wave-length used can cause dissociation of some iron carbonyl compounds, the experiment provides evidence that at least one step in the respiration is probably catalysed by an ironcontaining enzyme.

The characteristics of synthetic or assimilatory processes were then discussed in general terms and compared with those of the catabolic reactions. The former are mainly of a reductive nature, such as the conversion of carbon dioxide to carbohydrate in ordinary photosynthesis, or nitrogen fixation or the assimilation of sulphate or sulphite. The catabolic processes on the other hand, in their overall effect, are oxidative. Dr. Whittingham then discussed the various types of oxidation and considered the role of the cytochromes with particular reference to the valency changes which occur in the iron atom. The term oxidation may mean addition of oxygen to an organic compound, removal of hydrogen or just removal of electrons. In the oxidation of succinic acid there is first a removal of hydrogen atoms which is mediated through a flavoprotein complex; but ultimately there is transfer of electrons, which is catalysed by the iron-protoporphyrin complex of the cytochromes. The flavoprotein itself is complexed with a metal and transfers equivalents of hydrogen or electrons-one at a time-to the iron of cytochrome. The importance of the metal in this reaction has been demonstrated by showing that the activity of the flavoprotein is largely lost on dialysing it against cyanide. The exact manner with which the metal in the flavoprotein complex functions is still a matter for discussion.

Dr. Whittingham then discussed the oxidations, such as that catalysed by polyphenol oxidase. Reactions of this type are catalysed by coppercontaining enzymes which are widely distributed in higher plants, but their biological importance is still largely undefined. This type of oxidation may be only of minor importance, but the view is held by some workers that it may constitute an important method of electron transport and be an alternative pathway to that catalysed by the cytochrome-flavoprotein system.

Some aspects of photosynthesis were then discussed in detail. Dr. Whittingham mentioned the effect of iron deficiencies on the chlorophyll content of plants and he also described some observations showing that a deficiency of magnesium affects photosynthesis not only by reducing the chlorophyll content. It is likely that this is due to the fact that magnesium is an important constituent of several enzymic systems involved in the assimilation of carbon dioxide.

In the past few years evidence has accumulated showing that cytochromes, somewhat different in structure from those of the respiratory type, are also concerned with photosynthesis. Dr. Whittingham suggested that such a cytochrome system may supply a small, but nevertheless essential, part of the energy required to convert carbon dioxide into carbohydrate. He then discussed some recent work which showed that manganese played some part, not in the reduction of water to a hydroxyl-like radical, but in the oxygen-liberating part of photosynthesis. Another metal, molybdenum, is implicated in the nitrate reductase activity of Neurospora. Dr. Whittingham also considered a few other enzymic reactions which involve metals, such as the decarboxylation of keto-acids. He concluded with a few remarks about the role of potassium. This metal is required for the activity of the enzymes fructokinase and pyruvic acid kinase. But it is unlikely that the major cause of its nutritional importance is due to 
the co-factor requirements of these enzymes alone. It appears that a purely chemical explanation of the biological activity of potassium in plants, or for that matter in animals, has still to be found.

Sir Rudolph Peters and the audience warmly welcomed Sir John Russell, who in a short talk described how the recent advances in our knowledge of the deficiencies in trace metals were made partly by intelligent interpretation of mistakes in farming, partly by accident, but to a large extent by the application of spectrographic analysis. He gave some instances such as the important economic effects resulting from the realization that certain soils in Australia and New Zealand were deficient in molybdenum, zinc, cobalt or copper, or in combinations of these. He also described briefly the use of iron chelates in Florida.

Dr. D. P. Cuthbertson, director of the Rowett Research Institute, Bucksburn, Aberdeenshire, had most generously agreed to deputize for Mr. Hedley Marston, the head of the Nutrition Division of the (Australian) Commonwealth Scientific and Industrial Research Organization, who was prevented by illness from attending the meeting. Dr. Cuthbertson surveyed in a masterly manner the importance of metals in the nutrition of plants and, in a more cursory manner, of animals, and emphasized the economic importance of the recent work on the importance of the metal content of soil and pasture for the nutrition of sheep and cattle. In the first place, he directed attention to the very specific requirements for metals of both plants and animals. Thus sodium, which is most important in the electrolyte metabolism of animals, does not appear essential for any plant species studied. Certain plants have a very specific capacity for storing certain metals and sometimes in an unexpected manner; thus, legumes are particularly rich in calcium, deciduous fruits in potassium, and some tropical crops have high contents of manganese. Hickory accumulates aluminium and zine, and the Brazil nut stores barium. Metallic mercury has been observed in the seed capsules of Holosteum umbellatum. Iron, copper and vanadium are found in the respiratory pigments of hæmoglobin, hæmocyanin (Cephalopoda and Crustaceae) and hæmovanadin (Ascidae), respectively. Dr. Cuthbertson then mentioned some of the enzymes which contain metals as essential parts of their structures. Thus iron is present not only in hæmoglobin, but also in catalase, the various cytochromes and peroxidase. Zinc is present in carbonic anhydrase. Copper-protein complexes have been isolated from both animal and plant sources, some of which function as enzymes, such as polyphenol oxidase and ascorbic acid oxidase. In this connexion it is of interest to note that workers in the Rowett Research Institute have demonstrated the presence in herbage of a copper-peptide complex which has a greater biological effect than cupric ions in curing copper-deficiency in rats. Recently it has also been shown that molybdenum forms part of the prosthetic group of the enzymes xanthine oxidase and that of nitrate reductase.

Dr. Cuthbertson next discussed the deficiency diseases which may arise in plants or animals through lack of various metals. Lack of magnesium in plants, for example, produces characteristic changes in foliage, and deficiency of this metal is especially serious for fruit trees. Lack of potassium has also been shown to be particularly important for fruit trees. In Australia and New Zealand traces of molybdenum have improved clover production and both there and in the United States the rectification of zinc deficiency has greatly increased the citrus crop. Deficiencies of copper and cobalt have been particularly important for ruminants, and the rectification of such deficiencies in certain areas of Australia and New Zealand particularly has increased agricultural production in certain areas by amounts equivalent in value to many millions of pounds per year. There are also areas in the United Kingdom where grazing ruminants suffer from deficiency of cobalt or copper, and there are certain areas where the growth of horticultural crops-cauliflower in particular-is affected by molybdenum deficiency in the soil. There is now a considerable body of evidence showing the importance of trace-metal interaction-effect of the character of soil and of manurial treatment on the availability of metals to plants. Examples of such antagonism are provided by the interaction of iron and manganese and the observation that a high intake of molybdenum may inhibit assimilation of copper. In conclusion, Dr. Cuthbertson emphasized the interesting relationships which are being uncovered between the identification of metals as constituents of enzymes on the level of biochemistry, the nutritional importance of metals in the nutrition of plants and animals and the application of this knowledge to practical farming all over the world.

\section{EDMOND HALLEY: THE FIRST GEOPHYSICIST}

\section{By SIR EDWARD BULLARD, F.R.S.}

$\mathrm{T}$ HE three hundredth anniversary of the birth of Edmond Halley falls this week. When he was born on October 29, 1656, the kinematics of the solar system was understood; but the rest of physical science was little more than disconnected fragments. A few principles or laws, such as the isochronism of the pendulum and Snell's law of refraction, were known, but there was little sign of the immense power and utility of the combination of experiment and systematic theory.
By the time of Halley's death in 1742 , all this was changed and a body of knowledge and speculation existed that is recognizably the basis of modern science. It is scarcely an exaggeration to say that a single generation invented the technique, and discovered the content of physical science. What is more surprising, they were, in large measure, conscious of what they were doing. They believed that any fact was worth noting and any natural or industrial process worth investigating. As a young man, at 